\title{
Microstructure and Tribological Behavior of Self-lubricating (Si:N)-DLC/MAO Coatings on AZ80 Magnesium Substrate
}

Wei $Y A N G^{1,2)}$, Zhennan $D E N G^{3)}$, Dong $Z H A N G^{2)}$, Peiling $K^{2)}$ and Aiying $W A N G^{2 \dagger \dagger}$

1) School of Materials Science and Chemical Engineering, Xi'an Technological University, Xi'an 710032, China

2) Ningbo key laboratory of Marine Protection Materials, Ningbo Institute of Materials Technology and Engineering, Chinese Academy of Sciences, Ningbo 315201, China

3) Department of Prosthodontics, School \& Hospital of Stomatology, Wenzhou Medical College, Wenzhou 325027, China [Manuscript received 6 May 2013, in revised form 16 July 2013]

(C) The Chinese Society for Metals and Springer-Verlag Berlin Heidelberg

\begin{abstract}
The combined micro arc oxidation (MAO) and a hybrid beam deposition process was used to deposit duplex (Si:N)-DLC/MAO coatings on AZ80 magnesium alloy. The microstructure and composition of the duplex coatings were analyzed by Raman spectroscopy, X-ray photoelectron spectroscope (XPS), scanning electron microscope (SEM) and atomic force microscopy (AFM). Tribological behaviors of the coatings were studied by ball-on-disk friction test. It was found that the ID/IG ratio of the (Si:N)-DLC (diamond-like carbon) top films increases with decreasing $\mathrm{C}_{2} \mathrm{H}_{2} / \mathrm{N}_{2}$ ratio. The (Si:N)-DLC top film with $\mathrm{Si}_{3} \mathrm{~N}_{4}$ was formed on the MAO coated sample as the $\mathrm{C}_{2} \mathrm{H}_{2} / \mathrm{N}_{2}$ ratio was $10 \mathrm{sccm}: 5 \mathrm{sccm}$, which showed an increasing critical load compared with the pure DLC directly deposited on the $\mathrm{Mg}$ alloy substrate. As a result, the (Si:N)-DLC/MAO coating exhibited an advanced wear protection for the substrate.
\end{abstract}

\section{KEY WORDS: Mg alloy; Micro arc oxidation; DLC; Coating; Microstructure; Tribological behavior}

\section{Introduction}

There is a growing interest in magnesium alloys as structural materials for the aerospace and automotive industries due to the light weight ${ }^{[1,2]}$. However, magnesium alloys have the disadvantages of poor wear resistance and corrosion resistance ${ }^{[3-5]}$. DLC (diamond-like carbon) films are well known for their high hardness, good wear resistance and excellent corrosion resistance. They are usually deposited on other materials to improve their properties ${ }^{[6-10]}$. So it can be speculated that the DLC films for their excellent properties may be able to counterbalance the disadvantages of magnesium alloys.

It is known that the relatively high internal compressive stress in the film can result in poor adhesion $^{[11,12]}$. Therefore, an intermediate layer which provides improved load support is necessary

\footnotetext{
† Corresponding author. Prof., Ph.D.; Tel.: +86 574 86685170; Fax: +86 574 86685159; E-mail address: yangwei_smx@163.com (Aiying WANG)
}

DOI: $10.1007 / \mathrm{s} 40195-013-0265-\mathrm{y}$ to prevent the failure of DLC films. In most cases, a metallic film (e.g., $\mathrm{Cr}$ or $\mathrm{Ti}$ ) is used as the interlayer between DLC film and substrate to improve the adhesion ${ }^{[13-15]}$. However, these films have a poor corrosion resistance due to the existence of through-thickness defects and a large difference between the interlayer and $\mathrm{Mg}$ alloy substrate in galvanic series $^{[16,17]}$

Our previous work showed the possibilities of improving the adhesion of DLC film on magnesium alloy by substituting the pretreatment of interlayer formation with a process of micro arc oxidation (MAO) ${ }^{[18]}$. This MAO coating on magnesium alloy often exhibited a relatively high friction coefficient, and also suffered from corrosion failure due to the micropores on the coating surface ${ }^{[19,20]}$. It is proved that the duplex DLC/MAO coating could significantly improve the corrosion and wear resistance of the $\mathrm{Mg}$ substrate. Furthermore, metal doping seems a potential method to further improve the properties of DLC film efficiently ${ }^{[21-23]}$.

In this work, $\mathrm{Si}$ and $\mathrm{N}$ co-doping is employed to form the (Si:N)-DLC films with $\mathrm{Si}_{3} \mathrm{~N}_{4}$ on the MAO 
Table 1 Experimental parameters in the preparation process

\begin{tabular}{ccccccccc}
\hline \multirow{2}{*}{ Film } & \multicolumn{3}{c}{ Current (A) } & \multicolumn{3}{c}{ Gas flux $(\mathrm{mL} / \mathrm{min})$} & Deposition time (min) & Bias voltage (V) \\
\cline { 2 - 6 } & Sputtering source & Ion source & $\mathrm{Ar}$ & $\mathrm{N}_{2}$ & $\mathrm{C}_{2} \mathrm{H}_{2}$ & & \\
\hline (Si:N)-DLC-1 & 1.5 & 0.15 & 70 & 2 & 13 & 40 & -100 \\
(Si:N)-DLC-2 & 1.5 & 0.15 & 70 & 5 & 10 & 40 & -100 \\
(Si:N)-DLC-3 & 1.5 & 0.15 & 70 & 8 & 7 & 40 & -100 \\
\hline
\end{tabular}

coating surface by adjusting acetylene $\mathrm{C}_{2} \mathrm{H}_{2}$ and $\mathrm{N}_{2}$ ratio to improve the protection of DLC films on the $\mathrm{Mg}$ alloy substrate. It is speculated that $\mathrm{Si}$ and $\mathrm{N}$ co-doping could further improve the properties of the coated samples ${ }^{[24]}$. Furthermore, the MAO coating as the interlayer of (Si:N)-DLC films could be expected to improve the binding strength of the duplex coating with the substrate. Subsequently, the microstructure, binding strength, and tribological behavior of the duplex (Si:N)-DLC/MAO coatings are systematically investigated.

\section{Experimental}

\subsection{Preparation of duplex (Si:N)-DLC/MAO coatings}

Uncoated discs $(\Phi 20 \mathrm{~mm} \times 5 \mathrm{~mm})$ from AZ80 Mg alloy (Al 7.8-9.2, Mn 0.15-0.5, Zn 0.2-0.8, Mg balanced, in wt.\%) were mechanically polished to an average surface roughness of $R_{\mathrm{a}} \approx 23.5 \mathrm{~nm}$, followed by ultrasonic cleaning in acetone for $20 \mathrm{~min}$. The fabrication of the duplex (Si:N)-DLC/MAO coatings on AZ80 Mg alloy discs was performed by two steps including MAO and ion beam deposition technique. The MAO process was conducted on a direct-current (DC) pulsed electrical source, with frequency $500 \mathrm{~Hz}$ and duty cycle $5 \%$. A constant voltage about $300 \mathrm{~V}$ was used. The electrolyte was an aqueous solution, containing $5 \mathrm{~g} / \mathrm{L}$ sodium silicate $\left(\mathrm{Na}_{2} \mathrm{SiO}_{3}\right), 10 \mathrm{~g} / \mathrm{L}$ potassium hydroxide $(\mathrm{KOH})$, and $8 \mathrm{~g} / \mathrm{L}$ potassium fluoride $(\mathrm{KF})$ in distilled water. The temperature of the solutions was controlled bellow $35{ }^{\circ} \mathrm{C}$ during the oxidation. All the samples were treated in the electrolyte for $5 \mathrm{~min}$, resulting in a whole thickness of around $5 \mu \mathrm{m}$. After that, the DLC and (Si:N)DLC top films were deposited on the MAO coated samples and Si substrates by a hybrid ion beam deposition system (including a linear ion source (LIS) and a magnetron sputtering source), as shown in the literature [25]. The DLC film was deposited as the $\mathrm{C}_{2} \mathrm{H}_{2}$ gas flux was $15 \mathrm{sccm}$. Acetylene $\left(\mathrm{C}_{2} \mathrm{H}_{2}\right)$ and $\mathrm{N}_{2}$ ratio $\left(\mathrm{C}_{2} \mathrm{H}_{2} / \mathrm{N}_{2}\right)$ 13sccm:2sccm, 10sccm:5sccm, and $7 \mathrm{sccm}: 8 \mathrm{sccm})$ were introduced into the linear ion source to obtain the hydrocarbon ions for the deposition of (Si:N)-DLC films. Si was doped into (Si:N)DLC films by sputtering the Si target for $40 \mathrm{~min}$ with a sputtering current of $1.5 \mathrm{~A}$. The base pressure in the vacuum chamber was $8.67 \times 10^{-3} \mathrm{~Pa}$. A negative pulsed bias voltage of $-100 \mathrm{~V}$ was applied to the substrates. In the further text, we would use the terms "(Si:N)-DLC-1, (Si:N)-DLC-2, (Si:N)-DLC-3" to denote the three (Si:N)-DLC films, as the $\mathrm{C}_{2} \mathrm{H}_{2} / \mathrm{N}_{2}$ ra- tio was $13 \mathrm{~mL} / \mathrm{min}: 2 \mathrm{~mL} / \mathrm{min}, 10 \mathrm{~mL} / \mathrm{min}: 5 \mathrm{~mL} / \mathrm{min}$, and $7 \mathrm{~mL} / \mathrm{min}: 8 \mathrm{~mL} / \mathrm{min}$, respectively. The experimental parameters in the preparation process are shown in Table 1. The surface roughness and the thickness of the films are summarized in Table 2 .

Table 2 Thickness and roughness of the films

\begin{tabular}{ccc}
\hline Film & Thickness $(\mathrm{nm})$ & $R_{a}(\mathrm{~nm})$ \\
\hline (Si:N)-DLC-1 & 394.0 & 3.21 \\
(Si:N)-DLC-2 & 379.4 & 1.56 \\
(Si:N)-DLC-3 & 367.7 & 3.20 \\
\hline
\end{tabular}

\subsection{Coating characterization}

Field emission scanning electron microscope (FESEM) and atomic force microscopy (AFM) were performed to characterize the surface morphology of the obtained coatings. Energy dispersive X-ray spectrometer (EDS) was used to defect the element distribution of the coatings after friction tests. An X-ray photoelectron spectroscopy (XPS) with $\mathrm{Al} K_{\alpha}$ irradiation at pass energy of $160 \mathrm{eV}$ was used to characterize the chemical bonds of the films. The binding energies were referenced to the $\mathrm{C}$ 1s line at $285.0 \mathrm{eV}$. Raman spectroscopy with an incident $\mathrm{Ar}^{+}$beam at a wavelength of $514.5 \mathrm{~nm}$ was used to measure the atomic bonds of films.

\subsection{Property testing}

The adhesion of the films to the AZ80 substrates was assessed by a scratch tester performed on a Rockwell diamond indenter with a conical tip of $0.2 \mathrm{~mm}$ in radius. The normal load of the indenter was linearly ramped from the minimum to the maximum during scratching. Here, the minimum load and the maximum load were $1 \mathrm{~N}$ and $15 \mathrm{~N}$, respectively. In the test, the scratch length was $3.00 \mathrm{~mm}$ and the scratch speed was $0.2 \mathrm{~mm} / \mathrm{s}$. The tribological behavior of the treated samples was measured on a rotary ball-ondisk tribometer at room temperature with a relative humidity of $75 \%-80 \%$ under dry sliding conditions. During the tests, a $1 \mathrm{~N}$ contact load was applied on the samples through a steel ball (SUJ-2, HRC60) with a diameter of $6 \mathrm{~mm}$. All the tests were performed at a sliding speed of $0.1 \mathrm{~m} / \mathrm{s}$. The diameter of the sliding track was $2 \mathrm{~mm}$. After the friction test, the wear tracks were investigated using FESEM.

\section{Results and Discussion}

\subsection{Coating characteristics}

To obtain the microstructure of (Si:N)-DLC film 

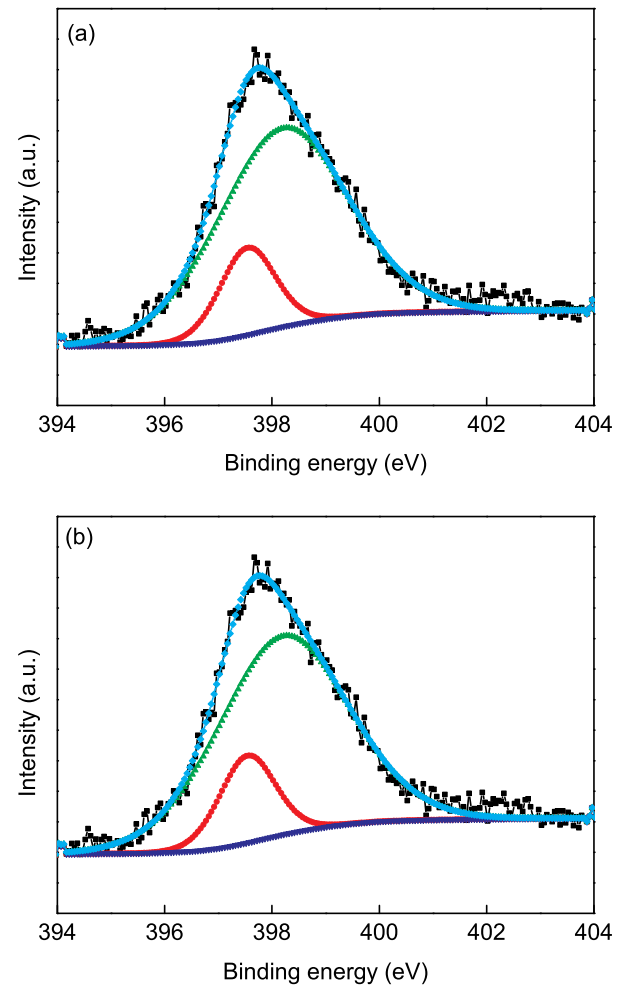

Fig. 1 Typical N1s (a) and Si2p (b) high-resolution XPS spectra of the (Si:N)-DLC film

with $\mathrm{Si}_{3} \mathrm{~N}_{4}$ by $\mathrm{Si}$ and $\mathrm{N}$ co-doping is one of the major purposes. The chemical bonds of the deposited films could be observed from the XPS spectra. The average $\mathrm{Si}$ and $\mathrm{N}$ concentration of the (Si:N)-DLC-2 film was 2.06 at.\% and 6.98 at.\%, respectively. Fig. 1(a) shows that the deconvolution of $\mathrm{N} 1 \mathrm{~s}$ peak of this top film gives two peaks at 397.5 and $398.3 \mathrm{eV}$, which are assigned to $\mathrm{Si}_{3} \mathrm{~N}_{4}$ and $-\mathrm{N}=$ bonds, respectively. The deconvolution of $\mathrm{Si} 2 \mathrm{p}$ peak of $(\mathrm{Si}: \mathrm{N})-\mathrm{DLC}$ top film was shown on Fig. 1(b), which gives a single peak at $101.7 \mathrm{eV}$ corresponding the typical $\mathrm{Si}_{3} \mathrm{~N}_{4}$ binding energy. It can be deduced that $\mathrm{Si}_{3} \mathrm{~N}_{4}$ was formed in the (Si:N)-DLC-2 film.

In experimental work, Raman spectra of (Si:N)DLC-1, (Si:N)-DLC-2 and (Si:N)-DLC-3 films are all evaluated by the G-band (around $1540 \mathrm{~cm}^{-1}$ ) and the $\mathrm{D}$ band (around $1345 \mathrm{~cm}^{-1}$ ), as shown in Fig. 2(a), indicating the typical diamond-like characteristics of the deposited films ${ }^{[26]}$. The $\mathrm{G}$ band is due to the bond stretching of all pairs of $\mathrm{sp}^{2}$ bond in both aromatic rings and carbon chains, and $\mathrm{D}$ band is due to the breathing modes of $\mathrm{sp}^{2}$ bond only in rings ${ }^{[2]}$. According to the $\mathrm{G}$ peak position and the intensity ratio of $\mathrm{D}$ peak to $\mathrm{G}$ peak $\left(\mathrm{I}_{\mathrm{D}} / \mathrm{I}_{\mathrm{G}}\right)$, the $\mathrm{sp}^{2} / \mathrm{sp}^{3}$ ratio of the DLC films can be characterized ${ }^{[28]}$. The $I_{\mathrm{D}} / I_{\mathrm{G}}$ values and the positions of $G$ peak are shown in Fig. 2(b). It is noted that the $G$ peak position shifted towards high wave number and the $\mathrm{I}_{\mathrm{D}} / \mathrm{I}_{\mathrm{G}}$ ratio also increased in the three ( $\mathrm{Si}: \mathrm{N})-\mathrm{DLC}$ films with the decreasing of $\mathrm{C}_{2} \mathrm{H}_{2} / \mathrm{N}_{2}$ ratio, implying the increased $\mathrm{sp}^{2} / \mathrm{sp}^{3}$ ratio in the top DLC films. The influence of the metal
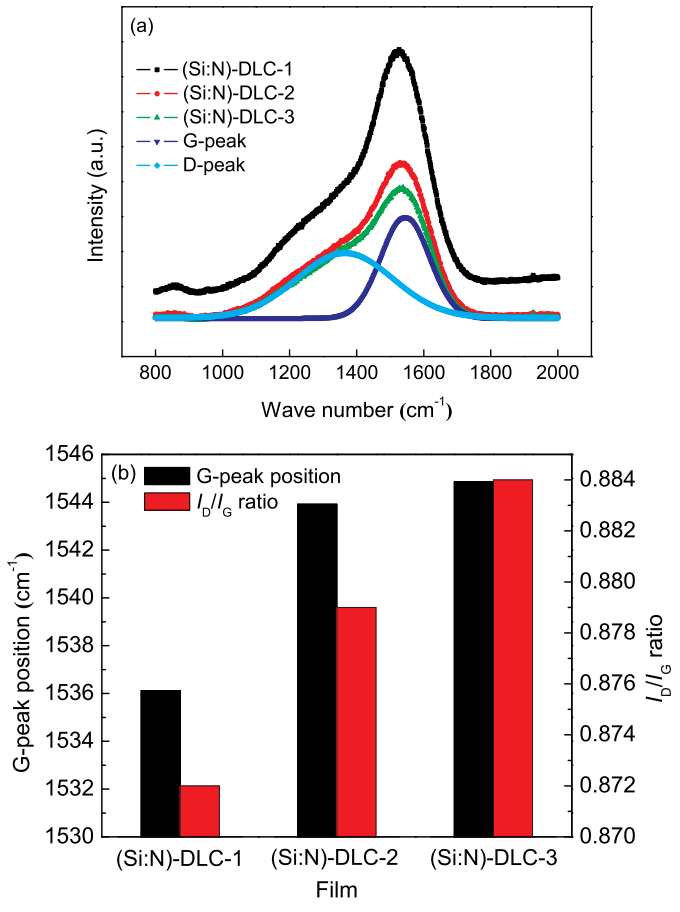

Fig. 2 Representative Raman spectra (a) and corresponding $\mathrm{G}$ peak position and $I_{\mathrm{D}} / I_{\mathrm{G}}$ (b) of the films

(Cr, Mo)-doping on the $\mathrm{sp}^{2} / \mathrm{sp}^{3}$ ratio in the DLC film had been reported due to the formation of carbide phase $^{[16,29]}$. So it could be speculated that the increasing formation of $-\mathrm{N}=$ bond in the $(\mathrm{Si}: \mathrm{N})-\mathrm{DLC}$ films resulted in the increase of $\mathrm{sp}^{2} / \mathrm{sp}^{3}$ ratio.

Typical AFM images of the three (Si:N)-DLC1, (Si:N)-DLC-2 and (Si:N)-DLC-3 films on the Si substrates are shown in Fig. 3. Compared with the (Si:N)-DLC-1 $\left(R_{\mathrm{a}} \approx 3.21 \mathrm{~nm}\right)$ and (Si:N)-DLC$3\left(R_{\mathrm{a}} \approx 3.20 \mathrm{~nm}\right)$ films, the (Si:N)-DLC-2 film surface tends to be smooth (Ra $\approx 1.56 \mathrm{~nm})$. Fig. 4 shows the surface morphologies of the MAO, (Si:N)DLC-1/MAO, (Si:N)-DLC-2/MAO and (Si:N)-DLC3/MAO coatings on AZ80 magnesium alloy. Fig. 4(a) shows the typical morphology of the MAO coating. It is very obvious that the MAO coating is characterized by micropores with different apertures. In the case of the three duplex coatings (Fig. 4(b)-Fig. 4(d)), all the areas on the surface show a porous surface microstructure inherent in the MAO coating. The surface microstructure of the duplex coatings is homogeneous with some of the surface area occupied by protuberances. The aperture of micropores on the duplex coating surface decreases due to the interstitial filled by the top films.

\subsection{Binding strength}

To obtain the high adhesion is another one of the major purposes for the (Si:N)-DLC protective films on magnesium alloy by substituting the interlayer formation with a pretreatment by MAO, and it has vital influences on the tribological behavior of the coated 

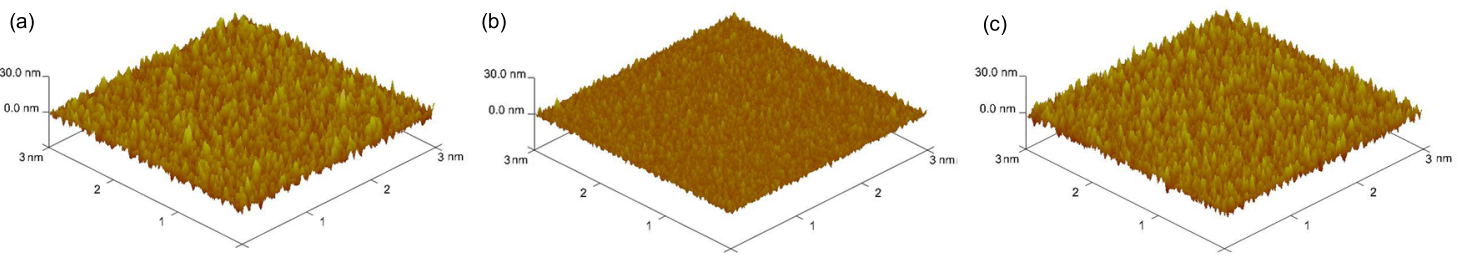

Fig. 3 AFM images of the films: (a) (Si:N)-DLC-1, (b) (Si:N)-DLC-2, (c) (Ti:N)-DLC-3

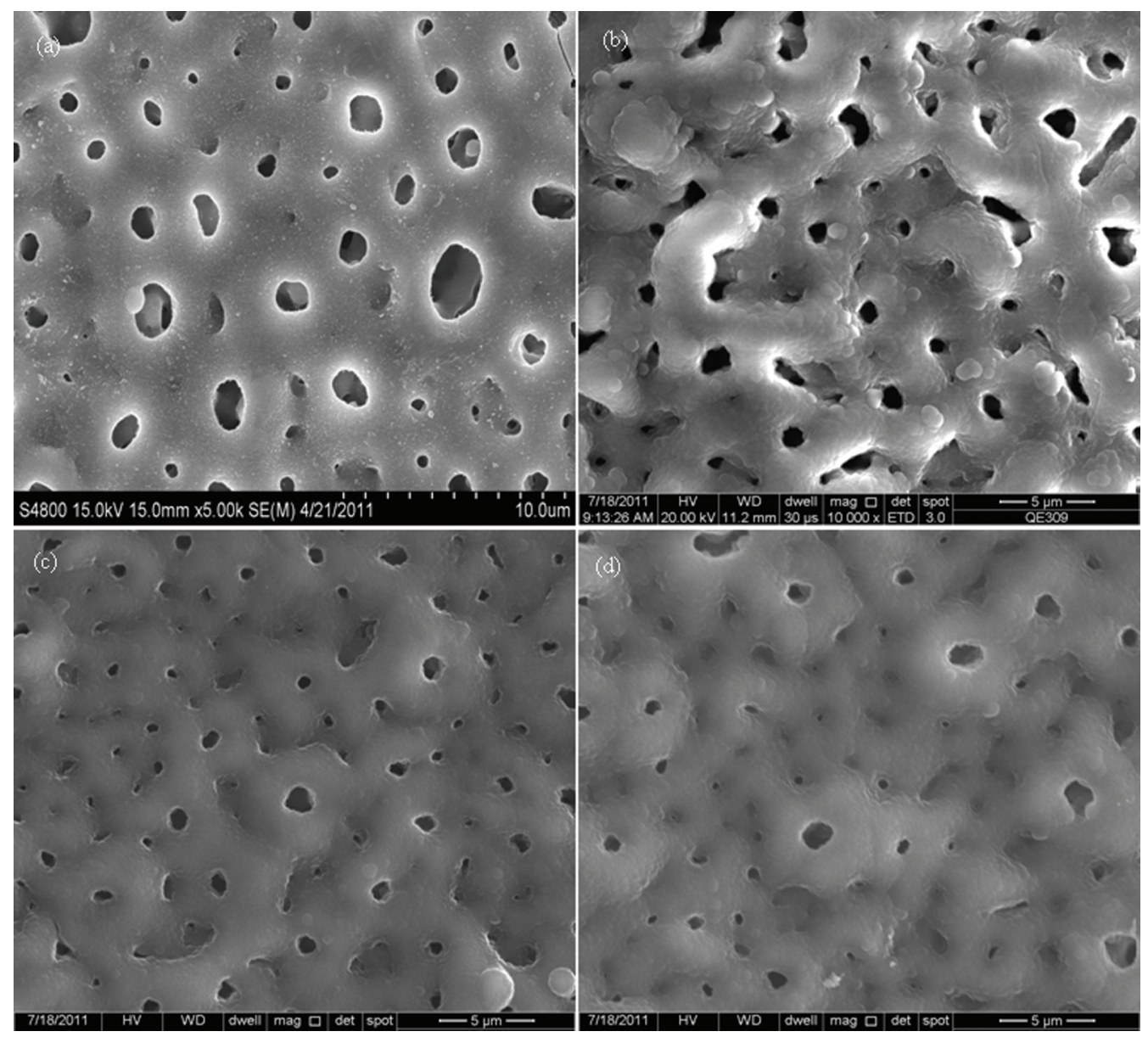

Fig. 4 Surface morphologies of the coatings: (a) MAO, (b) (Si:N)-DLC-1/MAO, (c) (Si:N)-DLC-2/MAO, (d) (Si:N)-DLC-3/MAO

samples. Fig. 5 shows the critical loads of the MAO, (Si:N)-DLC-1/MAO, (Si:N)-DLC-2/MAO and (Si:N)-DLC-3/MAO coatings with the AZ80 substrates. The results showed that all four coatings exhibited higher critical loads than the pure DLC film directly deposited on the $\mathrm{Mg}$ alloy substrate ${ }^{[16]}$. Furthermore, it can be deduced that the critical loads of the resulting four coatings in this research were strongly affected by the metallurgical bonding at the interface created by MAO treatment. It is also obtained that the (Si:N)-DLC-2/MAO coatings exhibited the highest critical load $(8.51 \mathrm{~N})$ among the four coatings.

\subsection{Tribological behavior}

The porous surface feature and improving bind- ing strength will lead to a special tribological behavior of the coated samples in the wear test. Fig. 6 presents the friction coefficient of the four coated samples against sliding distance. The frictional coefficient of the MAO coated sample jumped to 0.5 within the first few sliding cycles and then the friction coefficient remained stable during the whole wear test. The deposition of (Si:N)-DLC-1 and (Si:N)-DLC-3 films onto the MAO coating decreased the friction coefficient compared with the MAO coating. However, the values of the friction coefficient increase and they are unstable during the friction process. In the case of the duplex (Si:N)-DLC-2/MAO coating, it can be seen that the friction coefficient reached a stable value of about 0.1. From the XPS analysis, it is noted the (Si:N)-DLC-2 film with silicon nitride on the MAO 


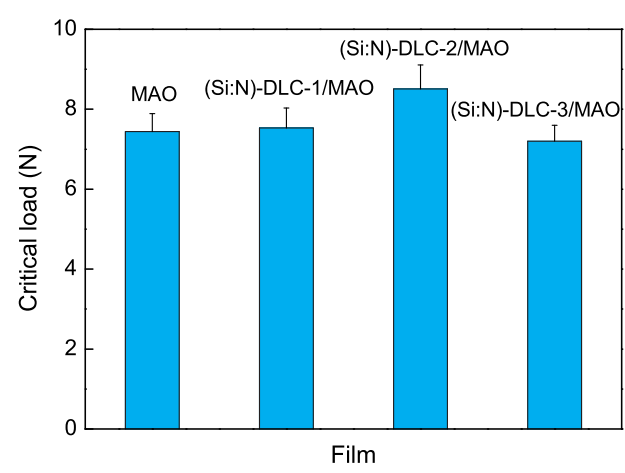

Fig. 5 Critical load of the coatings on AZ80 Mg alloy: (a) MAO, (b) (Si:N)-DLC-1/MAO, (c) (Si:N)-DLC2/MAO, (d) (Si:N)-DLC-3/MAO

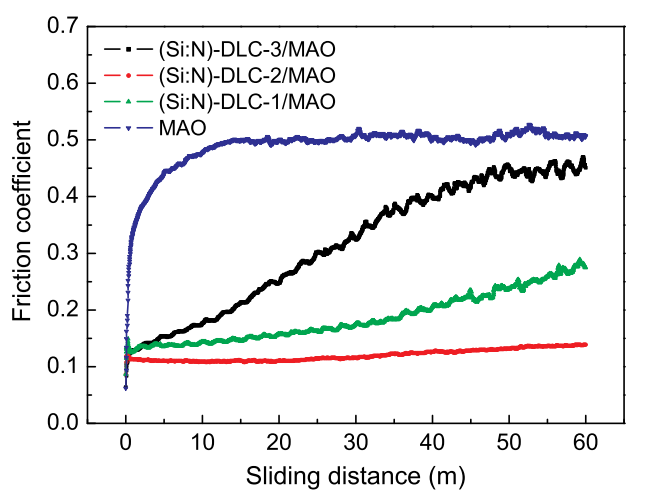

Fig. 6 Coefficient of the friction (COF) of the films coating AZ80 as a function of a sliding distance
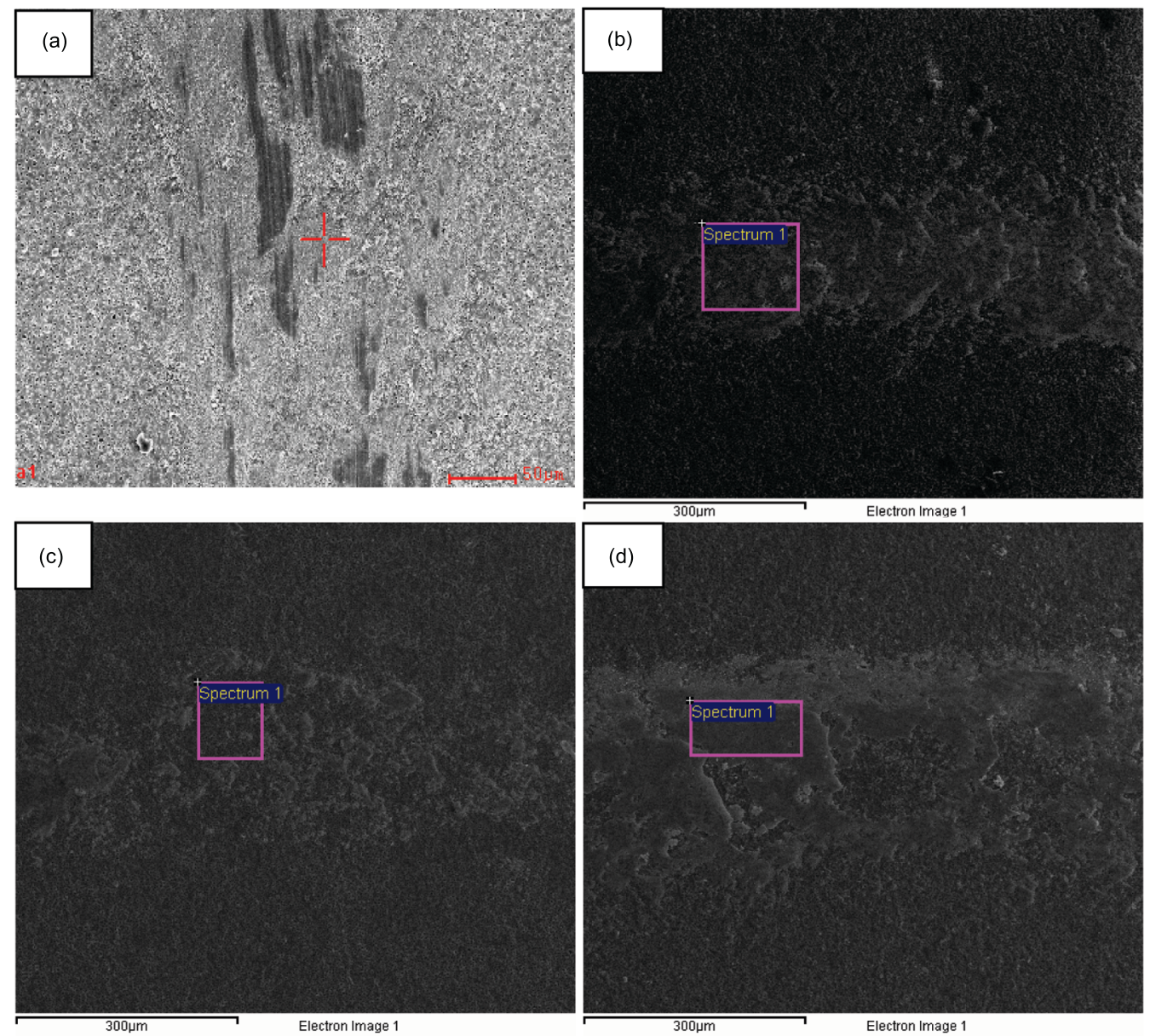

Fig. 7 OM images of the wear scar of the coatings: (a) MAO, (b) (Si:N)-DLC-1/MAO, (c) (Si:N)-DLC-2/MAO, (d) $(\mathrm{Si}: \mathrm{N})-\mathrm{DLC}-3 / \mathrm{MAO}$

coating surface could exhibit an excellent lubricating property ${ }^{[24]}$. Fig. 7 shows the surface profiles of the wear tracks in the four coated samples. The MAO specimen presented deep and broad wear tracks $(228.76 \mu \mathrm{m})$, and the MAO coating has peeled off from the $\mathrm{Mg}$ substrate. In the case of ( $\mathrm{Si}: \mathrm{N})-\mathrm{DLC}-1 / \mathrm{MAO}$ and (Si:N)-DLC-3/MAO coated samples, the wear tracks are also broad $(222.25 \mu \mathrm{m}$, and $250.65 \mu \mathrm{m})$. On the contrary, the wear track of the (Si:N)-DLC$2 / \mathrm{MAO}$ specimen is smooth and unnoticeable, and the width of wear track is only $136.94 \mu \mathrm{m}$. To investigate the wear mechanism of the (Si:N)-DLC/MAO coatings on AZ80 substrate, the composition of the wear tracks was analysed by EDS after friction tests, 
Table 3 Composition at wear tracks of the films in Fig. 7

\begin{tabular}{ccccccc}
\hline Sample & $\mathrm{C}$ & $\mathrm{O}$ & $\mathrm{Fe}$ & $\mathrm{Si}$ & $\mathrm{Mg}$ & $\mathrm{Al}$ \\
\hline MAO/AZ80 & & 57.15 & 35.98 & 1.83 & 4.20 & 0.83 \\
(Si:N)-DLC-1/MAO /AZ80 & 7.82 & 58.12 & 13.31 & 4.19 & 15.06 & 1.22 \\
(Si:N)-DLC-2/MAO /AZ80 & 28.46 & 33.87 & 0.17 & 8.16 & 26.72 & 2.43 \\
(Si:N)-DLC-3/MAO /AZ80 & 8.98 & 50.74 & 7.00 & 6.15 & 19.75 & 1.53 \\
\hline
\end{tabular}

shown in Table 3. It is confirmed that a large number of $\mathrm{Fe}$ and $\mathrm{O}$ are detected from the wear track of the MAO coated substrate. This reveals that the formation of the oxide due to the temperature spikes occurs at asperity contacts between the counter-body steel ball and the coating during the friction ${ }^{[21]}$. An amount of $\mathrm{O}$ and $\mathrm{Fe}$ were also discovered on the wear tracks of the (Si:N)-DLC-1/MAO and (Si:N)DLC-3/MAO coatings, which indicates that oxidation reaction also occurs. On the contrary, a little of $\mathrm{O}$ and Fe elements are detected, implying that the high-temperature oxidation process during the sliding process is observably restrained by the (Si:N)-DLC2 /MAO coating. Moreover, a large number of $\mathrm{C}$ is survived on this duplex coating compared with the other two duplex coatings, which provides an excellent lubricating property. So it is obtained that this (Si:N)-DLC-2/MAO duplex coating could greatly improve the protection of AZ80 magnesium alloy in this study.

\section{Conclusions}

The duplex (Si:N)-DLC/MAO coatings were successfully deposited on AZ80 magnesium alloy using MAO as pretreatment to improve their tribological property. In this study, the (Si:N)-DLC top film with $\mathrm{Si}_{3} \mathrm{~N}_{4}$ was obtained on the MAO coating surface. The $\mathrm{sp}^{2} / \mathrm{sp}^{3}$ ratio of these (Si:N)-DLC films decreased with increasing $\mathrm{C}_{2} \mathrm{H}_{2} / \mathrm{N}_{2}$ ratio. The MAO coating served as an intermediate layer for the (Si:N)DLC top coating provided an greatly increasing critical load with the soft $\mathrm{Mg}$ alloy substrate than the pure DLC film. The advanced wear protection of $\mathrm{Mg}$ alloy could be achieved by the duplex (Si:N)-DLC/MAO coating, which was due to its special microstructure and highest binding strength with the $\mathrm{Mg}$ alloy substrate.

\section{Acknowledgements}

The authors gratefully acknowledge the financial support of the National Natural Science Foundation of China (Grant No. 51201176), Industrialization Project of Education Department of Shaanxi Province (Grant No. 2012JC13) and Zhejiang Provincial Natural Science Foundation of China (Grant No. Y2110401).

\section{REFERENCES}

[1] J.E. Gray and B. Luan, J. Alloys Compd. 336 (2002) 88.

[2] R. Ambat, N.N. Aung and W. Zhou, Corros. Sci. 42 (2000) 1433.

[3] J. Dutta Majumdar, R. Galun, B.L. Mordlike and I.
Manna, Mater. Sci. Eng. A 361 (2003) 119.

[4] R. Gadow and D. Scherer, Surf. Coat. Technol. 151 (2002) 471.

[5] H. Hoche, H. Scheerer, D. Probst, E. Broszeit and C. Berger, Surf. Coat. Technol. 174 (2003) 1002.

[6] J. Choi, S. Nakao, J. Kim, M. Ikeyama and T. Kato, Diamond Relat. Mater. 16 (2007) 1361.

[7] A.H. Tan, Diamond Relat. Mater. 16 (2007) 467.

[8] R. Sharma, P.K. Barhai and N. Kumari, Thin Solid Films 516 (2008) 5397.

[9] H. Mohrbacher and J.P. Celis, Diamond Relat. Mater. 4 (1995) 1267.

[10] Ch. Schwarz, J. Heeg, M. Rosenberg and M.Wienecke, Diamond Relat. Mater. 17 (2008) 1685.

[11] Y. Oka, M. Nishijima, K. Hiraga and M. Yatsuzuka, Surf. Coat. Technol. 201 (2007) 6647.

[12] A.. Wang, K.R. Lee, J.P. Ahn and J.H. Han, Carbon 44 (2006) 1826.

[13] G.A. Zhang, P.X. Yan, P. Wang, Y.M. Chen, J.Y. Zhang, L.P. Wang and J.Y. Zhang, Surf. Coat. Technol. 202 (2008) 2684.

[14] G. Capote, L.F. Bonetti, L.V. Santos, V.J. TravaAiroldi and E.J. Corat, Thin Solid Films 516 (2008) 4011.

[15] Y.S. Li, Y. Tang, Q. Yang, C. Xiao and A. Hirose, Appl. Surf. Sci. 256 (2010) 7653.

[16] W. Dai, G.S. Wu and A.Y. Wang, Diamond Relat. Mater. 19 (2010) 1307.

[17] G.S. Wu, W. Dai, H. Zheng and A.Y. Wang, Surf. Coat. Technol. 205 (2010) 2067.

[18] W. Yang, A.Y. Wang, P.L. Ke and B.L. Jiang, Acta Metall. Sin. 47 (2011) 1535.

[19] J. Chen, R.C. Zeng, W.J. Huang, Z.Q. Zheng, Z.L. Wang and J. Wang, Nonferrous Met. Soc. China. 18 (2008) s361.

[20] J.Z. Li, Y.W. Tian and Z.X. Cui, Rare Metal Mater. Eng. 36 (2007) 528.

[21] T. Takeno, T. Sugawara, H. Miki and T. Takagi, Diamond Relat. Mater. 18 (2009) 1023.

[22] F. Zhao, H.X. Li, L. Ji, Y.J. Wang, H.D. Zhou and J.M. Chen, Diamond Relat. Mater. 19 (2010) 342.

[23] Y. H. Lin, H.D. Lin, C.K. Liu, M.W. Huang, J.R. Chen and H.C. Shih, Diamond Relat. Mater. 19 (2010) 1034.

[24] H. K. Li, Q. Liu, G.Q. Lin and C. Dong, Acta Metall. Sin. 45 (2009) 610.

[25] W. Dai, H. Zheng, G. Wu and A. Wang, Vacuum 85 (2010) 231.

[26] Y.F. Lu, S.M. Huang and Z. Sun, J. Appl. Phys. 87 (2000) 945

[27] J. B. Wu, C.Y. Chen, C. T. Shin, M. Y. Li, M. S. Leu and A. K. Li, Thin Solid Films, 517 (2008) 1141.

[28] Y.S. Li,Y. Tang, Q. Yang, C. Xiao and A. Hirose, Appl. Surf. Sci. 256 (2010) 7653.

[29] L. Ji, H. Li, F. Zhao, J. Chen and H. Zhou, Diamond Relat. Mater. 17 (2008) 1949. 